\title{
ELABORAÇÃO E ACEITABILIDADE DE PÃO DE QUEIJO ENRIQUECIDO COM ÔMEGA-3
}

\author{
MARIA BETHÂNIA BASILLI DE OLIVEIRA * \\ PATRÍCIA CARLA BARBOSA TREVIZAM MORAES**
}

\begin{abstract}
Este trabalho teve como objetivo a produção de pão de queijo enriquecido com ômega-3 em diferentes concentrações. Para a caracterização físico-química das amostras foram efetuadas as determinações do coeficiente de expansão, volume específico, umidade e $\mathrm{pH}$. As amostras também foram submetidas à análise de aceitação e intenção de compra. A amostra padrão apresentou os maiores valores para coeficiente de expansão, umidade e $\mathrm{pH}$ e menor volume específico. De acordo com os resultados obtidos na análise sensorial e intenção de compra, a amostra enriquecida com $1 \%$ de ômega-3 apresentou as melhores médias de aceitação entre os julgadores.
\end{abstract}

PALAVRAS-CHAVE: PÃO DE QUEIJO; ÔMEGA-3; ANÁLISES FÍSICO-QUÍMICAS; ANÁLISE SENSORIAL.

* Engenheira de Alimentos, Universidade Metodista de Piracicaba (UNIMEP), Santa Bárbara d’Oeste, SP (e-mail: mbeoliveira@yahoo.com.br).

** Doutora em Alimentos e Nutrição, Professora, Curso de Engenharia de Alimentos, UNIMEP, Santa Bárbara d’Oeste, SP (e-mail: pcmoraes@unimep.br). 


\section{INTRODUÇÃO}

Estudos têm comprovado que as dietas com quantidades adequadas de ácidos graxos poliinsaturados, como o ômega-3, desempenham papel importante na prevenção e tratamento de várias doenças como, por exemplo, as cardiovasculares (PITA et al., 2007).

Os ácidos graxos insaturados ômega-3 são encontrados em concentrações expressivas em lipídios de peixes e animais marinhos, especialmente os procedentes de regiões frias (PITA et al., 2007).

Dietas suplementares de peixes ou óleos de peixes e derivados de ômega-3 demostram os efeitos benéficos desses produtos. Com isso, nos últimos anos, vários medicamentos à base de óleos de peixes e/ou derivados surgiram no mercado, principalmente no mercado internacional (PITA et al., 2007). Efeitos são vistos com a ingestão diária de $2 \mathrm{~g} /$ dia de ômega-3 (ALVAREZ, 2008).

O pão de queijo, produto tradicional da culinária mineira, tem se tornado cada dia mais frequente na alimentação dos brasileiros, face às facilidades proporcionadas pelo processo de conservação da massa. A expansão desse produto no mercado extrapolou as fronteiras de Minas Gerais, e até mesmo do Brasil, propiciando o surgimento de novos fabricantes (INMETRO, 2008).

Por ser um produto bastante aceito entre a população brasileira, o pão de queijo atinge todas as faixas etárias e classes sociais. Sua produção vem crescendo continuadamente, aliada à expansão do mercado que inclui a exportação (MINIM et al., 2000).

Obtém-se pão de queijo a partir da mistura de polvilho com água ou leite, e posterior adição de queijo e sal. Ingredientes opcionais seriam ovos e/ou purê de batata, podendo-se também variar o tipo de polvilho (doce, azedo ou a mistura dos dois) (MINIM et al., 2000).

O pão de queijo pode ser encontrado no mercado já modelado e congelado, em pó para posterior adição de ingredientes ou ainda na forma de massa congelada (MINIM et al., 2000).

Além de constituir fonte reconhecida de carboidratos, o pão de queijo também é um produto de panificação isento de glúten. Tal característica o distingue como alimento alternativo para pacientes celíacos, alérgicos às proteínas do trigo (PEREIRA et al., 2004).

A adição de componentes funcionais, como o ômega-3, em alimentos já reconhecidos e aprovados pelos consumidores, pode representar importante possibilidade de agregar valor ao produto, além de atender ao interesse da população por alimentação saudável e rica em produtos com alto valor nutricional.

Os testes sensoriais são usados como garantia de qualidade de produtos por constituírem medida multidimensional integrada com vantagens importantes, como capacidade de identificar a presença ou ausência de diferenças perceptíveis, definição das características sensoriais de forma rápida e capacidade de detectar particularidades que não podem ser detectadas por outros procedimentos analíticos (MUNÕZ, CIVILLE e CARR, 1992).

Os testes afetivos que melhor avaliam a aceitabilidade de produtos e serviços são aqueles que utilizam os próprios consumidores desses produtos e os seus resultados proporcionam maiores oportunidades de ação (STONE e SIDEL, 1993). A análise da aceitação assume extrema importância por refletir o grau em que consumidores gostam ou desgostam de determinado produto. Deve ser realizada em laboratório de Análise Sensorial, utilizando-se equipe formada por 25 a 50 pessoas que sejam representativas do público que se deseja atingir (STONE e SIDEL, 1993).

O objetivo deste trabalho foi avaliar a influência da adição de diferentes concentrações de ômega-3 nas características físico-químicas e na aceitabilidade de pão de queijo.

\section{MATERIAL E MÉTODOS}

\subsection{MATERIAL}

Para elaboração do pão de queijo enriquecido com ômega-3 foram utilizadas as seguintes matérias-primas: polvilho azedo, fécula de mandioca, queijo parmesão ralado, água, óleo, ovo, leite integral, sal e ômega-3 (cápsulas de $1 \mathrm{~g}$, produzidas em farmácia de manipulação). Todas as matériasprimas foram adquiridas no comércio da cidade de Mogi-Guaçu (SP). 


\subsection{MÉTODOS}

\subsubsection{Preparo das amostras}

As formulações escolhidas para a condução dos testes estão apresentadas na Tabela 1. A elaboração dos pães de queijo foi realizada em laboratório da planta de processamento de alimentos da Universidade Metodista de Piracicaba, Campus Santa Bárbara d’Oeste.

\section{TABELA 1 - FORMULAÇÕES UTILIZADAS PARA A PRODUÇÃO DE PÃO DE QUEIJO TRADICIONAL E PÃO DE QUEIJO ENRIQUECIDO COM ÔMEGA-3}

\begin{tabular}{cccc}
\hline Matérias-Primas & $\begin{array}{c}\text { Pão dequeijo } \\
\text { tradicional }\end{array}$ & $\begin{array}{c}\text { Pão de queijo } \\
\text { enriquecidocom } \\
\text { de ômega-3 }\end{array}$ & $\begin{array}{c}\text { Pão de queijo } \\
\text { enriquecidocom } 3 \% \\
\text { de ômega-3 }\end{array}$ \\
\hline $\begin{array}{c}\text { Polvilho azedo } \\
\text { Fécula de mandioca }\end{array}$ & $27,06 \%$ & $9,12 \%$ & $8,93 \%$ \\
Queijo parmesão & $18,13 \%$ & $26,78 \%$ & $26,25 \%$ \\
ralado & $9,01 \%$ & $17,94 \%$ & $17,58 \%$ \\
Água & $8,11 \%$ & $8,92 \%$ & $8,74 \%$ \\
Óleo & $17,04 \%$ & $8,02 \%$ & $7,86 \%$ \\
O vo & $9,75 \%$ & $16,87 \%$ & $16,54 \%$ \\
Leite Integral & $1,70 \%$ & $9,66 \%$ & $9,46 \%$ \\
Sal & $-\cdots,--1,69 \%$ & $1,64 \%$ \\
Ômega-3 & & $1,0 \%$ & $3,0 \%$ \\
\hline
\end{tabular}

Formulação caseira.

A produção do pão de queijo enriquecido com ômega-3 foi realizada pela técnica com escaldamento, conforme a Figura 1.

\section{FIGURA 1 - FLUXOGRAMA DO PROCESSO DE FABRICAÇÃO DE PÃO DE QUEIJO ENRIQUECIDO COM ÔMEGA-3 - TÉCNICA DE ESCALDAMENTO}

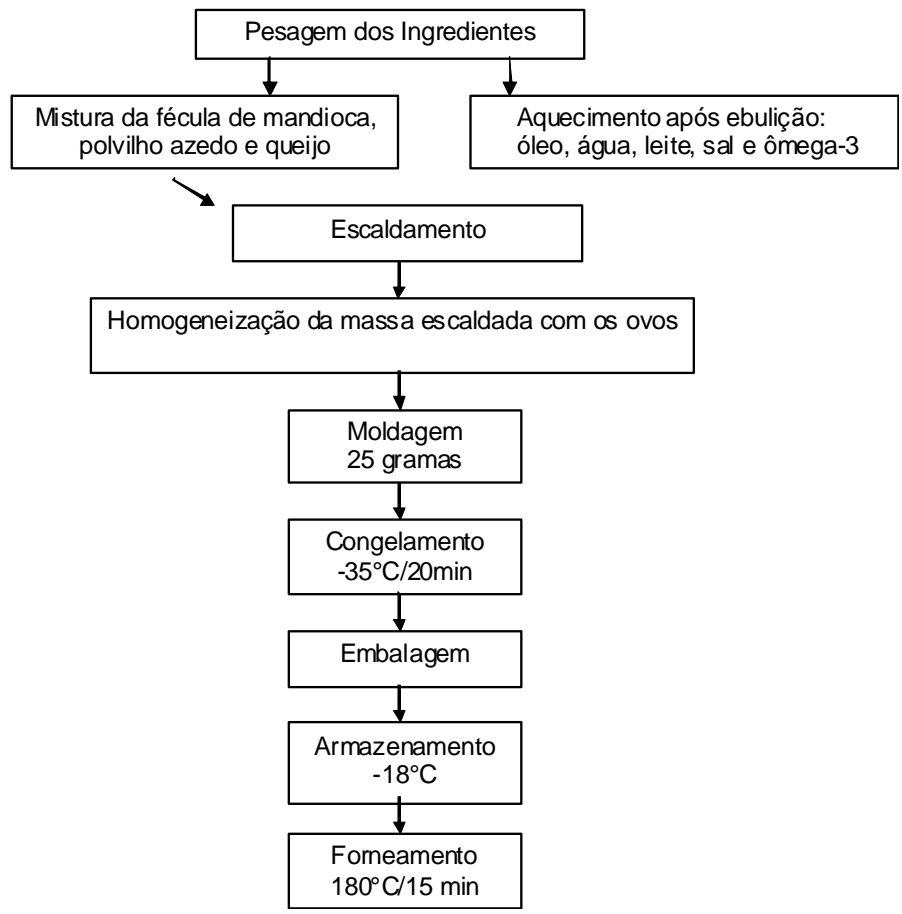




\subsubsection{Análises físico-químicas}

\subsubsection{Determinação do coeficiente de expansão}

Determinou-se o coeficiente de expansão dos pães de queijo (Ce) utilizando a equação 1 (SANTOS, 2006):

Em que:

$$
C e=\left(\frac{V_{2}-V_{1}}{V_{1}}\right) \times 100
$$

$\mathrm{Ce}=$ coeficiente de expansão (\%);

$V_{1}=$ volume da massa crua $\left(\mathrm{cm}^{3}\right) ;$

$V_{2}=$ volume do pão de queijo assado $\left(\mathrm{cm}^{3}\right)$.

\subsubsection{Determinação do volume específico}

O volume específico dos pães de queijo foi determinado pelo método de deslocamento de sementes de painço. Calculou-se o volume específico do pão de queijo utilizando a equação 2 (GRISWOLD, 1972):

$$
V_{e s p}=\frac{V}{m}
$$

Em que:

$V_{\text {esp }}=$ volume específico $\left(\mathrm{cm}^{3} / \mathrm{g}\right)$

$V=$ volume do pão de queijo $\left(\mathrm{cm}^{3}\right)$;

$m=$ massa do pão de queijo $(\mathrm{g})$.

\subsubsection{Determinação da umidade}

A umidade dos pães de queijo foi determinada em estufa de convecção forçada a $100^{\circ} \mathrm{C}$ até as amostras atingirem peso constante e calculada pela equação 3 (AOAC, 1970):

Em que:

$$
\operatorname{Ubu}(\%)=100\left(\frac{m_{u}-m_{s}}{m_{u}}\right)
$$

$m_{u}=$ massa úmida do produto;

$m_{s}=$ massa seca do produto;

Ubu = teor de umidade do produto em base úmida.

\subsubsection{Determinação do $\mathrm{pH}$}

Foram pesados 10 gramas de amostra em béquer e misturados com $100 \mathrm{~mL}$ de água destilada, com o auxílio de mixer. Após agitação, calibrou-se o pHgâmetro para posterior leitura do pH (OVIEDO, 1998).

\subsection{ANÁLISE SENSORIAL}

Os pães de queijo enriquecidos com ômega-3 em diferentes concentrações (pão de queijo tradicional, pão de queijo enriquecido com $1 \%$ de ômega-3 e pão de queijo enriquecido com $3 \%$ de ômega-3) foram submetidos à análise sensorial e de intenção de compra. Usou-se o teste de aceitação para avaliar os atributos aparência, cor, aroma, sabor, textura e impressão global das amostras. 
O teste foi realizado por julgadores voluntários, não treinados, no laboratório de Análise Sensorial da Universidade Metodista de Piracicaba (UNIMEP). Os julgadores receberam as amostras codificadas com algarismos de três dígitos, de forma monádica, em cabines individuais, segundo o delineamento de blocos completos balanceados (WALKELING e MaCFIEE, 1995).

Foram utilizadas fichas com escalas estruturadas de nove pontos (1= desgostei muitíssimo e 9 = gostei muitíssimo), conforme a Figura 2.

FIGURA 2 - MODELO DA FICHA UTILIZADA NO TESTE DE ACEITAÇÃO

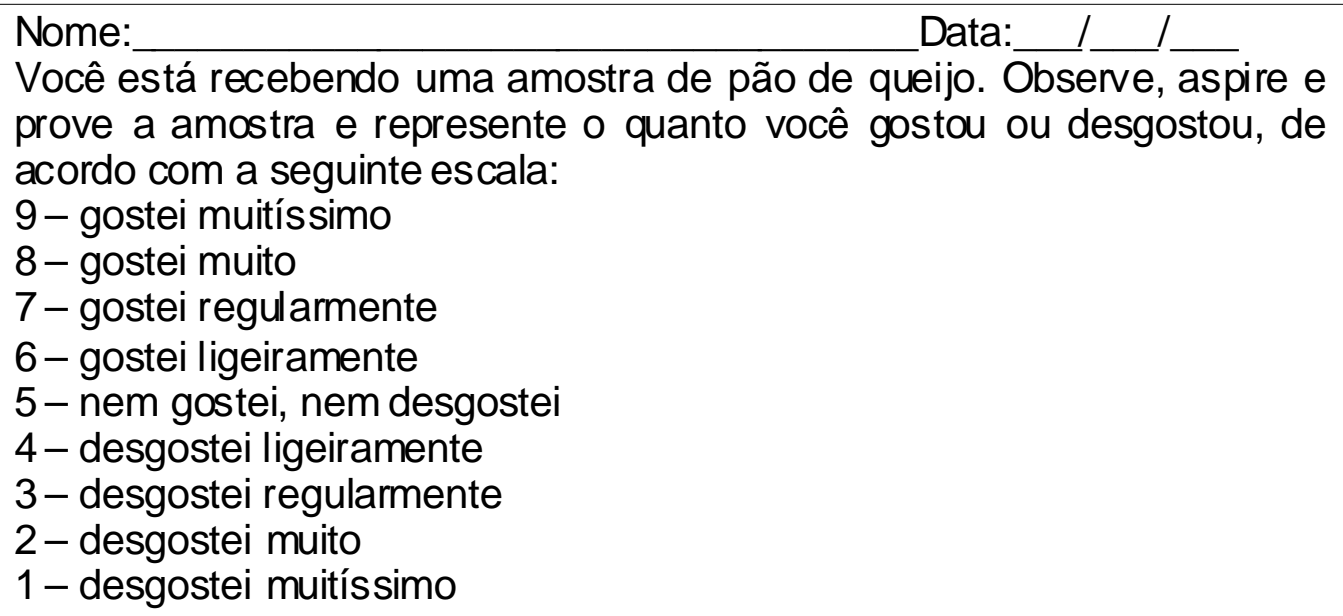

\begin{tabular}{|l|l|l|l|l|l|l|}
\hline Amostra & Aparência & Aroma & Cor & Sabor & Textura & $\begin{array}{l}\text { Impressão } \\
\text { Global }\end{array}$ \\
\hline & & & & & & \\
\hline & & & & & & \\
\hline
\end{tabular}

Na Figura 3 está representado o modelo da ficha utilizada no teste de intenção de compra.

\section{FIGURA 3 - MODELO DA FICHA UTILIZADA NO TESTE DE INTENÇÃO DE COMPRA}

Em relação à intenção de compra deste produto, qual seria a sua atitude?

Amostra número:

( ) Eu certamente $\overline{\mathrm{NÃO}}$ compraria

( ) Eu provavelmente NÃO compraria

( ) Eu tenho dúvida se compraria ou não

( ) Eu provavelmente compraria

( ) Eu certamente compraria

\subsection{ANÁLISE ESTATÍSTICADOS RESULTADOS}

Os resultados obtidos foram avaliados estatisticamente pela ANOVA e Teste de Médias de Tukey para identificar diferença significativa $(p>0,05)$ entre as formulações de pão de queijo, utilizandose o programa SAS (2003). 


\section{RESULTADOS E DISCUSSÃO}

\subsection{ANÁLISES FÍSICO-QUÍMICAS}

\subsubsection{Determinação do coeficiente de expansão}

De acordo com a Tabela 2, o coeficiente de expansão do pão de queijo diminuiu conforme se adicionou ômega-3 na formulação. A expansão possibilita a obtenção de miolo muito mais areado, leve e esponjoso. Pães de queijo com pouco crescimento geram miolos compactos, duros e gomosos.

Segundo APLEVICZ (2006), a relação entre a expansão e o peso dos pães está intimamente ligada ao grau de qualidade do produto.

\section{TABELA 2 - VALORES DO COEFICIENTE DE EXPANSÃO PARA AS DIFERENTES FORMULAÇÕES DE PÃO DE QUEIJO}

\begin{tabular}{cc}
\hline Amostras & Coeficiente de expansão (\%) \\
& \\
\hline Padrão & 278,96 \\
1\% ômega-3 & 142,35 \\
3\% ômega-3 & 32,88 \\
\hline
\end{tabular}

\subsubsection{Determinação do volume específico}

O volume específico (Tabela 3) das amostras aumentou de acordo com a adição de ômega-3.

O volume específico depende diretamente da expansão por ser calculado a partir do valor do índice de expansão. Assim, a expansão estabelece relação positiva com o volume (PEREIRA et al., 1999).

\section{TABELA 3 - VALORES DO VOLUME ESPECÍFICO PARA AS DIFERENTES FORMULAÇÕES DE PÃO DE QUEIJO}

\begin{tabular}{cc}
\hline Amostras & Volume específico $\left(\mathrm{cm}^{3} / \mathrm{g}\right)$ \\
\hline Padrão & 0,532 \\
1\% ômega-3 & 1,060 \\
$3 \%$ ômega-3 & 1,588 \\
\hline
\end{tabular}

\subsubsection{Determinação da umidade}

Em estudos realizados por APLEVICZ (2006), os valores de umidade ficaram abaixo de 18\%, conforme estabelecido pela RDC n²63 (BRASIL, 2005).

De acordo com a Tabela 4, os valores de umidade encontrados em pães de queijo com formulação padrão e enriquecidos com ômega-3 também apresentaram valores em torno de $18 \%$ (formulação padrão) e abaixo desse (enriquecido com ômega-3), estabelecendo coerência com a Resolução RDC n²63 (BRASIL, 2005). A umidade do pão de queijo diminuiu conforme se adicionou ômega-3 ao produto. 


\begin{tabular}{cc}
\hline Amostras & Umidade (\%) \\
\hline Padrão & 18,61 \\
1\% ômega-3 & 17,50 \\
$3 \%$ ômega-3 & 16,46 \\
\hline
\end{tabular}

\subsubsection{Determinação do pH}

Conforme se adicionou ômega-3 na formulação de pão de queijo, o pH do produto diminuiu (Tabela 5). Tal resultado pode ser atribuído ao fato do óleo de peixe apresentar pH em torno de 5,0 (SOUZA, MELO e BARRETO, 2007).

\section{TABELA 5 - VALORES DO PH PARA AS DIFERENTES FORMULAÇÕES DE PÃO DE QUEIJO}

\begin{tabular}{cc}
\hline Amostras & $\mathrm{pH}$ \\
& \\
\hline Padrão & 5,8 \\
1\% ômega-3 & 5,61 \\
$3 \%$ ômega-3 & 5,54 \\
\hline
\end{tabular}

\subsection{RESULTADOS DAANÁLISE SENSORIAL}

Os resultados obtidos no teste de médias de Tukey para aceitação de pão de queijo enriquecido com ômega-3 estão apresentados na Tabela 6.

TABELA 6 - ATRIBUTOS DAS DIFERENTES FORMULAÇÕES DE PÃO DE QUEIJO

\begin{tabular}{ccccc}
\hline Atributos & $\begin{array}{c}\text { Amostra } \\
\text { Padrão }\end{array}$ & $\begin{array}{c}\text { Amostra (1\% } \\
\text { de ômega-3) }\end{array}$ & $\begin{array}{c}\text { Amostra (3\% } \\
\text { de ômega-3) }\end{array}$ & DMS \\
\hline Aparência & $6,90^{\mathrm{b}}$ & $7,80^{\mathrm{a}}$ & $7,26^{\mathrm{a}, \mathrm{b}}$ & 0,835 \\
Aroma & $7,23^{\mathrm{a}}$ & $7,30^{\mathrm{a}}$ & $6,20^{\mathrm{b}}$ & 0,920 \\
Cor & $6,70^{\mathrm{b}}$ & $7,83^{\mathrm{a}}$ & $6,96^{\mathrm{b}}$ & 0,970 \\
Sabor & $7,46^{\mathrm{a}}$ & $7,60^{\mathrm{a}}$ & $5,66^{\mathrm{b}}$ & 1,030 \\
Textura & $7,40^{\mathrm{a}}$ & $7,70^{\mathrm{a}}$ & $7,46^{\mathrm{a}}$ & 0,680 \\
Impressão & $7,40^{\mathrm{a}, \mathrm{b}}$ & $7,90^{\mathrm{a}}$ & $6,93^{\mathrm{b}}$ & \\
Global & & & &
\end{tabular}

* DMS = Diferença média significativa entre as amostras.

* Letras iguais na mesma linha não apresentam diferença significativa entre si ao nível de significação testado $(0,05)$.

De acordo com a Tabela 6, a aparência da amostra padrão diferiu significativamente $(p<0,05)$ da amostra enriquecida com $1 \%$ de ômega- 3 , mas ambas não difiram significativamente $(p>0,05)$ da 
amostra enriquecida com 3\% de ômega-3. A amostra com 1\% de ômega-3 apresentou a maior média de aceitação.

Em relação ao aroma, a amostra padrão não diferiu significativamente $(p>0,05)$ da amostra enriquecida com $1 \%$ de ômega- 3 , mas ambas diferiram significativamente $(p<0,05)$ da amostra enriquecida com $3 \%$.

Para o atributo cor, a amostra padrão diferiu significativamente $(p<0,05)$ da amostra enriquecida com $1 \%$ de ômega-3, mas não da amostra enriquecida com $3 \%$. Pode-se observar que conforme se elevou a concentração de ômega-3 nas amostras, a intensidade da cor aumentou.

Para o atributo sabor, a amostra padrão não diferiu significativamente $(p>0,05)$ da amostra enriquecida com $1 \%$ de ômega-3, mas não da amostra enriquecida com $3 \%$ de ômega-3 devido ao sabor de peixe percebido no pão de queijo. A amostra com 1\% de ômega-3 apresentou a maior média de aceitação para sabor, indicando que pequenas concentrações de ômega-3 não alteram sensorialmente o produto ou, ainda, que as diferenças não são percebidas pelos julgadores.

Em relação à textura, as amostras analisadas não apresentaram diferença significativa $(p>0,05)$ entre si, evidenciando o mesmo nível de textura.

Quanto à impressão global, a amostra padrão não diferiu significativamente $(p>0,05)$ das amostras enriquecidas com ômega-3. A amostra enriquecida com 1\% de ômega-3 alcançou a maior média de aceitação para esse atributo.

Analisando as amostras de acordo com a intenção de compra dos consumidores (Figura 4) pode-se perceber que a amostra enriquecida com $1 \%$ de ômega- 3 liderou a classe "certamente compraria" e alcançou boa posição na opção "provavelmente compraria". Já a amostra enriquecida com 3\% de ômega-3 apresentou baixa aceitação. No gráfico, as primeiras colunas significam "certamente compraria", as segundas significam "provavelmente compraria", as terceiras "tenho dúvidas se compraria ou não", as quartas significam "provavelmente não compraria" e as últimas "certamente não compraria".

FIGURA 4 - GRÁFICO DE INTENÇÃO DE COMPRA DOS CONSUMIDORES

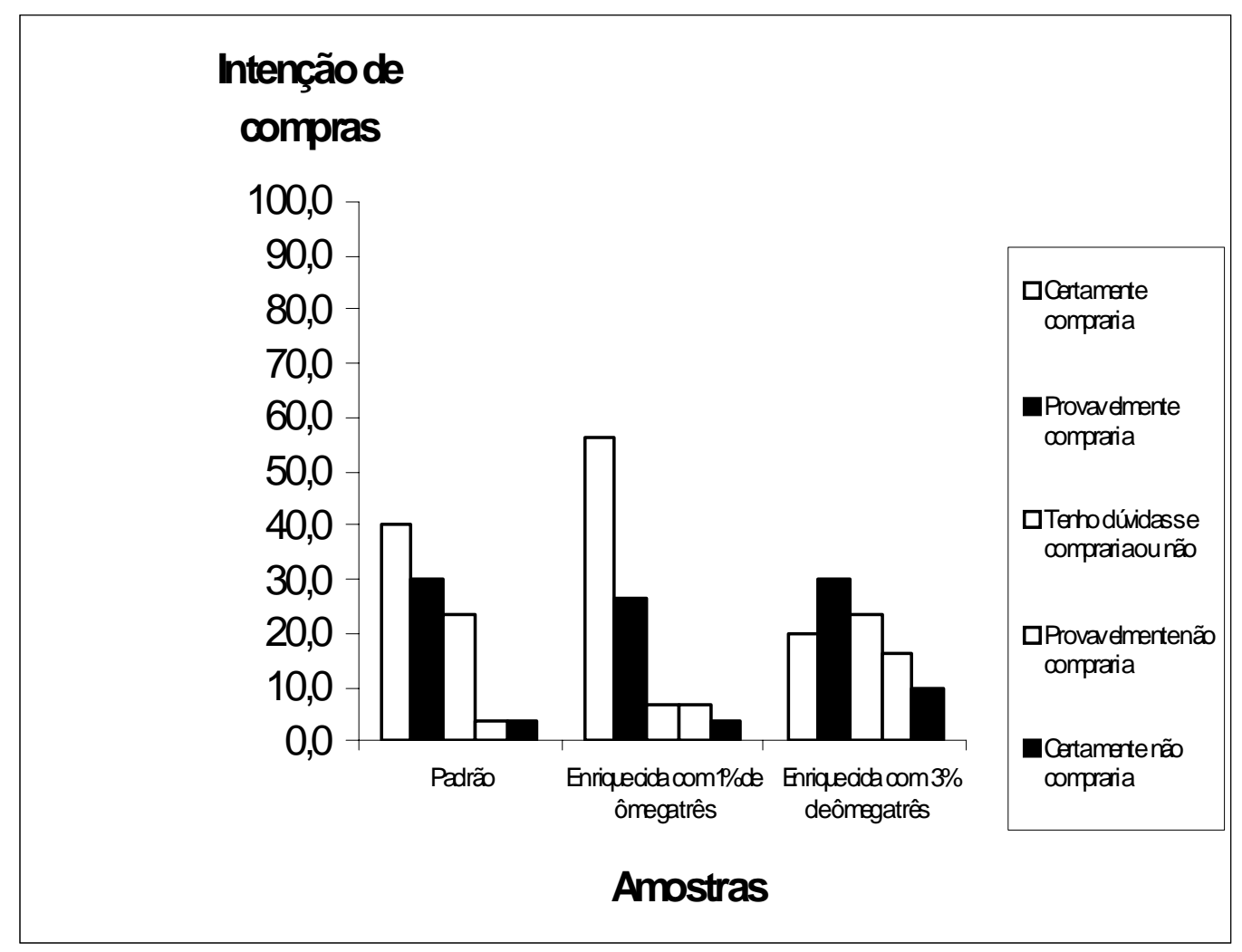


A formulação total de pão de queijo enriquecido com 1\% de ômega-3 foi de 1.866,67 gramas. Cada pão de queijo contém 25 gramas (peso total) com 0,25 gramas de ômega-3. Utilizando-se cálculos de proporções do consumo ideal de ômega-3 diário com o peso total, calculam-se quantos pães de queijo enriquecidos com 1\% de ômega-3 devem ser consumidos diariamente para que se obtenha o efeito desejado.

\section{CONCLUSÃO}

A adição de 3\% de ômega-3 (óleo de peixe) prejudicou o crescimento do pão de queijo. $\mathrm{O}$ volume específico foi maior para a concentração de 3\% de ômega-3 e a umidade e pH diminuíram com o aumento da concentração.

A textura foi o único atributo que não apresentou diferença significativa $(p>0,05)$ entre as amostras, indicando que a concentração de ômega-3 não altera essa característica sensorial.

A amostra 2 (enriquecida com 1\% de ômega-3) apresentou as maiores médias de aceitação para todos os atributos avaliados, não evidenciando diferença significativa $(p>0,05)$ em relação à amostra padrão para os atributos aroma, sabor, textura e impressão global.

A adição de 1\% de ômega-3 não prejudicou a aceitação do produto, sendo tal concentração possível de ser usada em pães de queijo com o objetivo de aumentar a ingestão de ômega-3.

Quanto à intenção de compra, mais de $50 \%$ dos julgadores certamente comprariam o pão de queijo com 1\% de ômega-3, indicando que o produto atingiu o objetivo proposto.

\section{ABSTRACT}

\section{ELABORATION AND ACCEPTABILITY OF CHEESE BREAD ENRICHED WITH OMEGA-3}

The work had as objective the cheese bread production enriched with omega-3 in different concentrations. For physical-chemical characterization of samples: determination of the coefficient of expansion, determination the specific volume, moisture, and $\mathrm{pH}$ were accomplished. The samples were also submitted to acceptance analysis and intention to purchase. The standard sample showed the highest values for expansion coefficient, moisture and $\mathrm{pH}$ and lower specific volume. According to the results of sensory analysis and intention to purchase, the sample enriched with $1 \%$ of omega-3 presented the best means of acceptance among judges.

KEY-WORDS: CHEESE BREAD; OMEGA-3; PHYSICOCHEMICAL ANALYSIS; SENSORY ANALYSIS.

\section{REFERÊNCIAS}

1 ALVAREZ, J. Benefícios do consumo de peixes na saúde humana. Universidade Federal de Minas Gerais. 2008. Disponível em: <http://www.icb.ufmg.br>. Acesso em: 27 mar 2008.

2 OAC. Association of Official Agricultural Chemists. Official methods of analyses of the AOAC International. Washington, DC, 1970.

3 APLEVICZ, K. S. Caracterização de produtos de panificação à base de féculas de mandioca nativas e modificadas. 2006. 131 p. Dissertação (Mestrado em Ciência e Tecnologia de Alimentos), Universidade Estadual de Ponta Grossa, Ponto Grossa, 2006. Disponível em: <http://www.uepg.br>. Acesso em: 29 mar 2008.

4 BRASIL. Ministério da Saúde. Agência Nacional de Vigilância Sanitária. Resolução RDC - 263. Regulamento técnico para produtos de cereais, amidos, farinhas e farelos. Brasília, 2005. Disponível em: <http://www.anvisa.gov.br>. Acesso em: 22 nov 2009.

5 GRISWOLD, R. M. Estudo experimental dos alimentos. São Paulo: Editora da Universidade de São Paulo, 1972. $469 \mathrm{p}$.

6 INMETRO. Instituto Nacional de Metrologia, Normalização e Qualidade Industrial. Portal do consumidor. Disponível em: <http://www.inmetro.gov.br>. Acesso em: 27 mar 2008.

7 MINIM, V. P. R; MACHADO, P. T.; CANAVESI, E.; PIROZI, M.R. Perfil sensorial e aceitabilidade de diferentes formulações de pão de queijo. Ciência e Tecnologia de Alimentos, Campinas/SP 2000. 6 p. Disponível em: <http:// www.scielo.br>. Acesso em: 28 mar 2008. 
8 MUNÕZ, A. M.; CIVILLE, G. V.; CARR, B. T. Sensory evaluation in quality control. New York: Van NostrandReinhold, 1992. $240 \mathrm{p}$

9 OVIEDO, P. Secagem do amido fermentado de mandioca: modificação química relacionada com a propriedade de expansão e características físico-químicas. 1998. 114 p. Tese (Doutorado em Tecnologia de Alimentos), Faculdade de Engenharia de Alimentos, Universidade Estadual de Campinas, Campinas, 1998.

10 PEREIRA, J.; CIACCO, C. F.; VILELA, E. R.; PEREIRA, R. G. F. A. Função dos ingredientes na consistência da massa e nas características do pão de queijo. Ciência e Tecnologia de Alimentos, Campinas/SP, 2004. 7 p. Disponível em: <http://www.scielo.br>. Acesso em: 28 mar 2008

11 PEREIRA, J.; CIACCO, C. F.; VILELA, E. R.; TEIXEIRA, A. L. Féculas fermentadas na fabricação de biscoitos: estudo de fontes alternativas. Campinas/SP, Ciência e Tecnologia de Alimentos, 1999. 7 p. Disponível em: <http:// www.scielo.br>. Acesso em: 28 mar 2008.

12 PITA, M. C. G.; NETO, E. P.; CARVALHO, P. R.; JUNIOR, C. X. M. Efeito da suplementação de linhaça, óleo de canola e vitamina $\mathrm{E}$ na dieta sobre as concentrações de ácidos graxos poliinsaturados em ovos de galinha. Arquivo Brasileiro de Medicina Veterinária e Zootecnia. São Paulo, 2007. 9 p. Disponível em: <http://www.scielo.br>. Acesso em: 25 mar 2008.

13 SAS Institute. SAS user's guide: statistics. Cary, USA, 2003.

14 SANTOS, J. R. U. Desenvolvimento de pão de queijo funcional pela incorporação de isolado protéico de soja e polidextrose. 2006. 319 p. Dissertação (Mestrado em Tecnologia de Alimentos) Faculdade de Engenharia de Alimentos, Universidade Estadual de Campinas, Campinas, 2006.

15 SOUZA, F. B.; MELO F. A. A.; BARRETO, H. C. S. Caracterização físico-química de óleo de peixe Leporinus friderici (Aracú-cabeça-gorda). In: CONGRESSO BRASILEIRO DE QUÍMICA, 2., 2007, Natal/RN. 47 CBQ. Anais ... Disponível em: <http://www.abq.org.br>. Acesso em: 28 mar 2008.

16 STONE, H.; SIDEL, J. Sensory evaluation practices. New York: Academic Press, 1993. 338 p.

17 WAKELING, I. N.; MACFIE, J. H. Designing consumer trials balanced for first and higher orders of carry-over effect when only a subset of $\kappa$ samples from $\tau$ may be tested. Food Quality and Preference, New York, v. 6, n.4, p. 299$308,1995$. 